\title{
CATÁLISE ELETROQUÍMICA DA REDUÇÃO DO BROMATO EM SUPERFÍCIES MODIFICADAS POR FILMES
} DE MOLIBDÊNIO

\author{
Mauro Bertotti \\ Instituto de Química - Universidade de São Paulo - Av. Prof. Lineu Prestes, 748 - 05508-900 - São Paulo - SP \\ Derek Pletcher \\ Department of Chemistry - The University - Southampton SO17 1BJ - England
}

Recebido em 9/4/97; aceito em 7/08/97

\begin{abstract}
CATALYSIS OF THE BROMATE REDUCTION AT A MOLYBDENUM OXIDE MODIFIED ELECTRODE. In this paper some studies concerning the electroreduction of Mo(VI) in sulphuric acid solutions are described. We have shown that at suitable experimental conditions very stable molybdenum oxide films can be electrochemically deposited at glassy carbon electrodes, the reduction of bromate occurring at less negative potentials on the modified surface. Coulometric experiments have shown that bromide is not the only product of the catalytic bromate reduction by the molybdenum film and species like $\mathrm{BrO}_{2}$ may have part in this process. Based on chronoamperometric curves recorded at $\mathbf{- 0 . 6 0} \mathrm{V}$, analytical curves have been obtained for the reduction of bromate in the 0.1 $0.8 \mathrm{mM}$ range, a limit of detection of $20 \mu \mathrm{M}$ for bromate being determined.
\end{abstract}

Keywords: molybdenum films; bromate; modified electrodes.

\section{INTRODUCÃO}

A modificação de superfícies de eletrodos objetivando a diminuição da sobretensão de processos redox envolvendo diversas espécies químicas continua a ser uma área de crescente interesse em eletroanalítica ${ }^{1-5}$. Pesquisas no sentido de sintetizar mediadores seletivos são norteadas pela capacidade de interação entre substrato e catalisador, da qual também depende a extensão da diminuição da sobretensão do processo de transferência de elétrons. Além de estudos vinculados à interação química entre mediador e substrato, outro campo de interesse consiste nas alternativas para imobilizar o mediador na superfície de eletrodos sólidos. Técnicas largamente empregadas incluem a fixação do mediador na superfície do eletrodo por meio de processos de adsorção ou ligação covalente. Mistura do catalisador com pasta de carbono ou fixação em matrizes poliméricas eletroquimicamente depositadas constituem-se em métodos bastante utilizados atualmente face às facilidades experimentais. No que concerne ao material imobilizado deve-se entretanto salientar alguns aspectos a serem considerados, os quais incluem a perda de atividade catalítica em razão do processo de fixação no eletrodo ou mesmo a solubilização da espécie catalítica na solução de trabalho com conseqüente diminuição da vida útil do sensor.

Ainda no que diz respeito à catálise de processos de transferência de elétrons mediados quimicamente, uma outra possibilidade bastante atraente relaciona-se à utilização de óxidos de compostos de transição com estado de oxidação misto, os quais são excelentes mediadores para transferência de átomos de oxigênio em processos de redução de oxi-ânions. A fixação e estabilização destes compostos em eletrodos de carbono vítreo pode ser realizada adequadamente por métodos eletroquímicos em determinadas condições de acidez, nas quais depósitos porosos e estáveis são fixados firmemente a eletrodos de carbono vítreo. Neste contexto, cabe ressaltar a utilização de óxidos de tungstênio e molibdênio eletroquimicamente depositados em superfícies de carbono vítreo ${ }^{6-8}$. Estes compostos mostraram-se excelentes mediadores da redução de clorato e bromato, ânions reduzidos em potenciais bem menos negativos nas superfícies modificadas, e em alguns casos mecanismos detalhados são apresentados para explicar o processo catalítico ${ }^{8-10}$.
O presente trabalho explora algumas propriedades de filmes de molibdênio depositados eletroquimicamente em meio sulfúrico a partir de soluções contendo Mo(VI). Estudos anteriores revelaram a possibilidade da catáise da redução de bromato em superfícies contendo tais óxidos de molibdênio e algumas observações experimentais mostraram-se bastante interessantes no que diz respeito ao aumento da corrente catalítica ao longo do tempo em experimentos cronoamperométricos realizados na faixa de potenciais de $-0,50$ a $-0,70 \mathrm{~V}^{10}$. Explicações para tal fenômeno basearam-se na existência de diferentes camadas de molibdênio com atividades catalíticas distintas, as quais coexistem em equilíbrios influenciados por fatores experimentais como acidez e concentração do bromato. Na composição do filme é provável que óxidos não estequiométricos tenham participação relevante e nestes o número de oxidação do molibdênio ou o grau de hidrogenação parecem ser bastante variados, conforme propõem Wang e Dong ${ }^{8}$. Os mesmos autores sugerem que os filmes são uniformes e compactos, com espessura da ordem de $0,1 \mu \mathrm{m}$. Neste sentido, o presente trabalho pretende abordar algumas possibilidades referentes à preparação e emprego de eletrodos quimicamente modificados com óxidos mistos de molibdênio para análise de bromato. A seleção de condições experimentais adequadas para obtenção dos filmes em eletrodos de carbono vítreo e microeletrodos de fibra de carbono será comentada com base em aspectos como durabilidade, porosidade, estabilidade química e atividade catalítica frente a bromato. Adicionalmente, dados referentes à redução do substrato e possíveis produtos são discutidos baseando-se em resultados coletados em experimentos coulométricos.

\section{PARTE EXPERIMENTAL}

Reagentes: Todos as soluções utilizadas foram preparadas a partir de reagentes de grau analítico. Soluções estoque de Mo(VI) (10 mM) foram preparadas a partir do sal sódico $\left(\mathrm{Na}_{2} \mathrm{MoO}_{4} \cdot 2 \mathrm{H}_{2} \mathrm{O}\right.$, Merck) e padronizadas de acordo com procedimento clássico recomendado na literatura ${ }^{11}$. As soluções foram preparadas com água purificada no sistema Millipore e previamente aos experimentos voltamétricos e coulométricos estas foram deareadas exaustivamente passando-se um fluxo de nitrogênio. 
Estudos voltaméricos e cronoamperométricos. Os experimentos eletroquímicos realizados com um eletrodo de carbono vítreo (área $=0,2 \mathrm{~cm}^{2}$ ) foram conduzidos numa célula de vidro adaptada com um capilar de Luggin, empregando-se um sistema de 3 eletrodos. Como eletrodo auxiliar utilizou-se um anel de platina e um eletrodo de calomelano ( $\mathrm{KCl}$ saturado) serviu como eletrodo de referência. Voltamogramas registrados com microeletrodo de fibra de carbono foram obtidos em célula de compartimento único, utilizando-se um sistema de 2 eletrodos. Os microeletrodos foram construídos selando-se microfibras de carbono ou platina em tubos de vidro, aquecendo-se os mesmos com uma resistência elétrica. A superfície do eletrodo de carbono vítreo e dos microeletrodos foi lixada adequadamente com mistura aquosa contendo alumina $(0,3 \mu \mathrm{m})$. Empregou-se um potenciostato construído na oficina de eletrônica do Departamento de Química da Universidade de Southampton e um registrador Gould série 60000.

Estudos coulométricos. Experimentos envolvendo a redução eletroquímica do $\mathrm{Mo}(\mathrm{VI})$ a potencial controlado foram realizados em eletrodo de disco de carbono vítreo de $1,5 \mathrm{~cm}$ de raio em célula coulométrica apropriada contendo compartimento para solução de trabalho e eletrodos de carbono vítreo e referência (calomelano com capilar de Luggin) e outro compartimento contendo solução de sulfato de sódio $0,5 \mathrm{M}$ e uma espiral de platina como eletrodo auxiliar. Nos experimentos voltamétricos realizados com a solução de trabalho antes e após eletrólises a potencial controlado, protegeu-se a mesma de eventual contaminação de cloreto proveniente do eletrodo de referência colocando-se este eletrodo em solução de $\mathrm{Na}_{2} \mathrm{SO}_{4}$ 0,5 $\mathrm{M}$ contida em tubo de vidro em cuja extremidade adaptouse um disco de vidro sinterizado.

Determinação de $\mathrm{pH}$. $\mathrm{O}$ pH das soluções foi medido com aparelho Jenway 3010. O eletrodo de vidro combinado foi convenientemente calibrado empregando-se tampão fosfato com $\mathrm{pH}=7,0$.

Determinação de Br-. Determinações analíticas do brometo gerado via redução de bromato em experimentos coulométricos foram realizadas voltametricamente utilizando-se microeletrodo de mercúrio, medindo-se a corrente anódica referente ao processo de oxidação antecipada do mercúrio na presença do haleto. O microeletrodo de mercúrio foi preparado pela eletrodeposição de mercúrio em microeletrodo de platina $(\mathrm{r}=$ $12,5 \mu \mathrm{m})$ a partir de solução deaerada contendo $\mathrm{Hg}\left(\mathrm{NO}_{3}\right)_{2}$ $20 \mathrm{mM}+\mathrm{KNO}_{3} 0,5 \mathrm{M}$, aplicando-se potencial de $0 \mathrm{~V}$ contra eletrodo de referência de calomelano ${ }^{12}$. Este foi convenientemente isolado da solução eletrolítica a fim de impedir a difusão de ions cloreto. Não houve necessidade de agitação uma vez que o transporte de material para um microeletrodo é extremamente efetivo em razão da difusão radial $^{13}$.

\section{RESULTADOS E DISCUSSÃO}

\section{Redução eletroquímica do Mo(VI)}

A química do $\mathrm{Mo}(\mathrm{VI})$ constitui-se em área de pesquisa extremamente complexa por causa das inúmeras espécies existentes em solução aquosa ${ }^{14,15}$. Estas coexistem em equilíbrios lábeis deslocados por fatores experimentais, formando-se espécies com graus de polimerização bastante variados. Tal complexidade reflete-se nas propriedades eletroquímicas de soluções de Mo(VI), para as quais são encontrados comportamentos extremamente diferentes em função da concentração de Mo(VI), acidez das soluções e tipo de eletrodos de trabalho ${ }^{16,17}$. Um fato bastante característico relaciona-se à possibilidade de deposição de óxidos estáveis na superfície de eletrodos sólidos, ratificando observações experimentais sobre a supressão de ondas polarográficas trabalhando-se com soluções relativamente concentradas em $\mathrm{Mo}(\mathrm{VI})^{18}$.

Estudos envolvendo a redução catódica do Mo(VI) foram realizados com soluções de Mo(VI) $1 \mathrm{mM}$ em diferentes valores de $\mathrm{pH}$ na faixa de 1,5 a 9,0. Todos os experimentos foram conduzidos com microeletrodo de fibra de carbono $(\mathrm{r}=4 \mu \mathrm{m})$ e após cada varredura este foi polido objetivando-se o registro de novos voltamogramas em superfície isenta de óxidos de molibdênio. Em meio com pH acima de 7, onde a espécie predominante é o ânion tetraoxigenado $\mathrm{MoO}_{4}{ }^{\circ}$, não foi observado qualquer processo de redução eletroquímica até $-1,00 \mathrm{~V}$, ratificando dados da literatura ${ }^{19}$. A gradual acidificação conduz a soluções com comportamento eletroquímico parecido àquele apresentado nos voltamogramas da figura 1 , observando-se deslocamento do processo de redução para potenciais mais positivos à medida que o pH diminui. Em concordância com resultados relatados na literatura ${ }^{10}$, verificou-se que a redução eletroquímica do Mo(VI) é extremamente dependente do $\mathrm{pH}$ em razão da existência de diferentes espécies em solução e à provável participação de prótons no processo de redução eletroquímica, obtendo-se em pH próximo a 3 a onda catódica de maior intensidade.

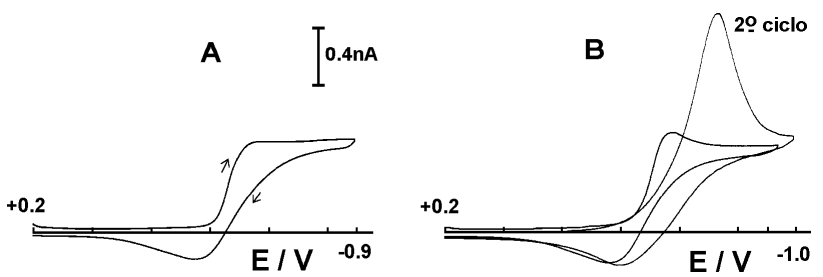

Figura 1. Voltamograma de solução de $\mathrm{Mo}(\mathrm{VI}) 1 \mathrm{mM}+\mathrm{Na}_{2} \mathrm{SO}_{4} 50$ $m M+\mathrm{H}_{2} \mathrm{SO}_{4}(\mathrm{pH}=3,05)$ obtido com microeletrodo de fibra de carbono (A) $(r=4 \mu \mathrm{m}, v=20 \mathrm{mV} / \mathrm{s})$. Em B apresentam-se os voltamogramas resultantes de 2 varreduras consecutivas.

A formação de óxidos de molibdênio na superfície de eletrodos sólidos pode ser evidenciada nos voltamogramas apresentados na figura 1 , obtidos com microeletrodo de fibra de carbono em solução de $\mathrm{Mo}(\mathrm{VI}) 1 \mathrm{mM}+\mathrm{Na}_{2} \mathrm{SO}_{4} 50 \mathrm{mM}$ em $\mathrm{H}_{2} \mathrm{SO}_{4}(\mathrm{pH}=3,05)$. Observa-se na figura $1 \mathrm{~A}$ que durante a varredura de potencial no sentido de valores mais negativos aparece um processo de redução com potencial de meia-onda de $-0,46 \mathrm{~V}$, relativo à redução de $\mathrm{Mo}(\mathrm{VI})$. Entretanto, a existência do componente anódico na varredura reversa não seria esperada trabalhando-se com microeletrodo de raio $=4 \mu \mathrm{m}$ e velocidade de varredura $=20 \mathrm{mV} / \mathrm{s}$, uma vez que, nestas condições, o componente radial da difusão é extremamente elevado obtendo-se facilmente uma situação de estado estacionário na qual o perfil do voltamograma é o mesmo qualquer que seja o sentido da varredura ${ }^{13}$. A explicação plausível para o fato reside na acumulação de material na superfície do eletrodo durante o processo de redução, o qual é oxidado eletroquimicamente ao completar-se o ciclo voltamétrico. Na figura $1 \mathrm{~B}$ tal conclusão é ratificada ao efetuar-se segunda ciclagem de potencial, observando-se deposição ainda maior de material na superfície do eletrodo.

\section{Preparação e características dos filmes de molibdênio}

Constatando-se que o processo de redução eletroquímica ocorre com maior intensidade em soluções acidificadas de Mo(VI) com $\mathrm{pH}=3$, estudos foram realizados com o intuito de verificar a formação de filmes em eletrodo de carbono vítreo ciclando-se seguidamente o potencial no intervalo compreendido entre $+0,20$ e $-1,10 \mathrm{~V}$. A figura 2 mostra o contínuo crescimento do filme, resultado da formação de várias camadas de material provavelmente constituído por óxidos reduzidos de molibdênio do tipo $\mathrm{H}_{\mathrm{x}} \mathrm{MoO}_{3-\mathrm{x}}$ ou $\mathrm{MoO}_{3-\mathrm{x}}$, caracterizados como "bronzes" ou óxidos nos quais o metal apresenta estado de oxidação misto em razão de um preenchimento parcial do orbital d. A constatação da formação do filme durante o experimento eletroquímico pôde ser feita a olho nu pela observação de depósito preto formado na superfície do 
eletrodo de trabalho após alguns ciclos de potencial. Tais compostos têm sido exaustivamente estudados em razão de suas propriedades condutoras, catalíticas e eletrocrômicas, as quais são bastante distintas de acordo com o método empregado para obtenção do material ${ }^{20-22}$.

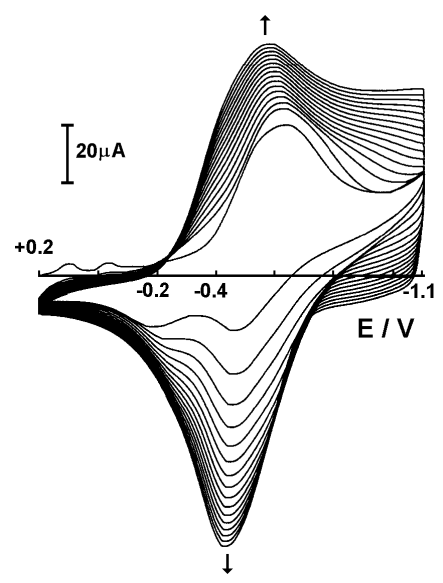

Figura 2. Voltamogramas consecutivos de solução de Mo(VI) $1 \mathrm{mM}+$ $\mathrm{Na}_{2} \mathrm{SO}_{4} 5 \mathrm{O} \mathrm{mM}+\mathrm{H}_{2} \mathrm{SO}_{4}(\mathrm{pH}=3,05)$ obtidos com eletrodo de disco de carbono vítreo $(v=200 \mathrm{mV} / \mathrm{s})$.

Estudos referentes à estabilidade do eletrodo modificado foram realizados após preparação do mesmo (10 ciclos entre $+0,20$ e $-1,10 \mathrm{~V}$ em solução contendo $\mathrm{Mo}(\mathrm{VI}) 1 \mathrm{mM}+\mathrm{H}_{2} \mathrm{SO}_{4}$ $1 \mathrm{mM}+\mathrm{Na}_{2} \mathrm{SO}_{4} 50 \mathrm{mM}$ e lavagem com água deionizada) e ciclagem contínua em solução de eletrólito suporte sem Mo(VI) $\left(\mathrm{H}_{2} \mathrm{SO}_{4} 1 \mathrm{mM}+\mathrm{Na}_{2} \mathrm{SO}_{4} 50 \mathrm{mM}\right)$. O voltamograma do filme de molibdênio em solução sem Mo(VI) apresenta as mesmas características daquele obtido após o processo de ciclagem na solução contendo Mo(VI) (vide voltamograma A, Figura 4). Observou-se também que mesmo após 800 ciclos o voltamograma do material depositado no eletrodo de carbono vítreo permanece virtualmente inalterado, confirmando a estabilidade química e eletroquímica do filme nestas condições experimentais. Todavia, em experimentos repetidos com o mesmo filme em solução sulfúrica em $\mathrm{pH}=2$ (na ausência de $\mathrm{Mo}(\mathrm{VI})$ ) verificou-se queda no sinal de corrente durante as sucessivas ciclagens de potencial. Possíveis justificativas para a gradual perda de sinal em meio mais ácido relacionam-se à lenta dissolução dos óxidos de molibdênio responsáveis pelo processo catalítico e eventualmente presentes nas camadas mais superficiais. Uma possibilidade alternativa para esta diminuição do sinal de corrente poderia estar relacionada a um processo de recristalização ou envelhecimento do filme em meio mais ácido como resultado de fenômeno de desidratação, produzindo-se desta maneira uma camada inativa no que concerne à redução de bromato.

Característica importante dos filmes de molibdênio gerados eletroquimicamente refere-se à sua porosidade. Filmes gerados pela varredura de potencial entre $+0,20$ e $-1,10 \mathrm{~V}$ em solução contendo $\mathrm{Mo}(\mathrm{VI}) 1 \mathrm{mM}+\mathrm{H}_{2} \mathrm{SO}_{4} 1 \mathrm{mM}+\mathrm{Na}_{2} \mathrm{SO}_{4} 50$ $\mathrm{mM}$ apresentaram-se relativamente porosos perante a redução de $\mathrm{Fe}(\mathrm{CN})_{6}{ }^{3-}$ quando o número de ciclos foi pequeno (até 5 ciclos). Experimentos foram realizados com o eletrodo modificado em solução contendo o eletrólito suporte sem Mo(VI) com o objetivo de verificar a permeabilidade do filme no que concerne ao processo de redução eletroquímica do $\mathrm{Fe}(\mathrm{CN})_{6}{ }^{3-}$. Voltamogramas obtidos em solução do eletrólito suporte contendo também a espécie eletroativa foram registrados com o eletrodo de carbono vítreo antes (A) e após (B) a modificação, observando-se a excelente concordância entre as duas situações no que se refere à redução reversível do $\operatorname{Fe}(\mathrm{CN})_{6}{ }^{3-}$
(Figura 3). Desta forma, a ocorrência de processo de transferência de elétrons empregando-se o eletrodo modificado com o filme de molibdênio demonstra a porosidade da camada de óxidos de molibdênio ou sua capacidade para intermediar o processo redox. Entretanto, observou-se que esta propriedade não pode ser estendida para filmes mais espessos obtidos pelo aumento no número de ciclos. Em tais casos, o filme de molibdênio eletroquimicamente depositado apresentou-se como efetiva barreira à redução eletroquímica do $\mathrm{Fe}(\mathrm{CN})_{6}{ }^{3-}$, conforme observa-se nos voltamogramas $\mathrm{C}$ e $\mathrm{D}$ da figura 3 .

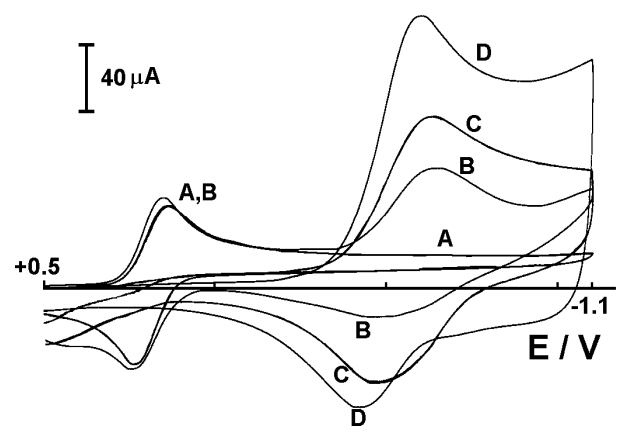

Figura 3. Voltamogramas de solução de $\mathrm{Fe}(\mathrm{CN})_{6}^{3-} 1 \mathrm{mM} \mathrm{em} \mathrm{Na}_{2} \mathrm{SO}_{4} 50 \mathrm{mM}$ $+\mathrm{H}_{2} \mathrm{SO}_{4}(\mathrm{pH}=3,05)$ utilizando $(A)$ eletrodo de carbono vítreo e $(B),(C)$ e (D) eletrodos modificados por filme de molibdênio preparados pela ciclagem em solução contendo o eletrólito suporte $+\mathrm{Mo}(\mathrm{VI}) \operatorname{lmM}(B=5$ ciclos, $C=$ 20 ciclos, $D=40$ ciclos). Velocidade de varredura $=200 \mathrm{mV} / \mathrm{s}$.

\section{Catálise da redução do bromato}

Diversos estudos apresentados na literatura demonstram ser a redução eletroquímica do bromato processo altamente irreversível em eletrodos não modificados ${ }^{6,23,24}$. Entretanto, no eletrodo gotejante de mercúrio tal processo ocorre com diminuição da sobretensão em meio contendo complexos orgânicos de Mo(VI), cujas formas reduzidas constituem-se em eficientes mediadores do processo de transferência de elétrons envolvendo bromato ${ }^{23}$. De maneira similar, em eletrodos de carbono vítreo em cuja superfície depositaram-se óxidos não estequiométricos de tungstênio, Kulesza e Faulkner ${ }^{6}$ observaram a catálise da redução catódica deste ânion em processo que ocorre em $-0,10 \mathrm{~V}$ (vs SCE).

Com o intuito de verificar as propriedades catalíticas do filme de molibdênio perante a redução de bromato, voltamogramas de solução acidificada contendo o ânion foram registrados antes e após processo de deposição eletroquímica do filme de molibdênio. Conforme mostra a figura 4 , o bromato não é eletroativo na faixa de potencial abrangendo $+0,20$ a $-1,10 \mathrm{~V}$ utilizando-se o eletrodo de carbono vítreo. Após o processo de modificação do eletrodo pela deposição do filme de molibdênio, o pico catódico em $-0,60 \mathrm{~V}$ teve sua corrente aumentada na presença de bromato $2 \mathrm{mM}$ confirmando o efeito catalítico. Tal constatação também pode ser ratificada pela observação da ausência do componente anódico do voltamograma do eletrodo modificado em meio contendo bromato, uma vez que nesta condição existe consumo da espécie reduzida de molibdênio pelo substrato.

Em face à boa estabilidade do eletrodo modificado de molibdênio em meio de $\mathrm{pH}=3$ e à constatação de processo catalítico envolvendo a redução de bromato nesta superfície, estudos subseqüentes objetivaram avaliar a possibilidade de utilização do eletrodo como sensor para determinação quantitativa de íons bromato. Utilizou-se como técnica analítica a cronoamperometria, fixandose o potencial em região onde observou-se a geração eletroquímica de espécies de molibdênio cataliticamente ativas perante a redução do substrato $(-0,60 \mathrm{~V})$. A figura 5 apresenta curvas cronoamperométricas registradas com o eletrodo modificado antes e após adição de bromato $2 \mathrm{mM}$ à solução contendo o eletrólito 
suporte sem Mo(VI). Observa-se nitidamente o efeito catalítico dos óxidos reduzidos de molibdênio no que tange ao processo de redução de bromato, assim como a irreversibilidade do processo eletroquímico referente a este substrato em superfície não modificada. Cronoamperogramas reprodútiveis $(n=5)$ foram obtidos com o eletrodo modificado na solução contendo brometo, demonstrando a estabilidade do filme de molibdênio. A curva analítica na faixa de 0,10 a $0,80 \mathrm{mM}\left(\mathrm{r}^{2}=0,999\right)$ em bromato foi obtida com o eletrodo modificado em solução sulfúrica de $\mathrm{pH}=3$ medindose a corrente em intervalo de tempo adequado (40 s). Limites de detecção da ordem de $20 \mu \mathrm{M}$ em bromato foram estimados com base na reprodutibilidade das respostas cronoamperométricas do eletrodo modificado em solução sem bromato e comparação com sinal obtido na presença do analito. Valores inferiores podem ser atingidos controlando-se a espessura do filme de forma a reduzir o sinal analítico referente ao branco, mesmo que nestas condições o sinal catalítico seja ligeiramente menor. Investigações preliminares relacionadas à variação do sinal analítico para o substrato trabalhando-se com filmes de diferentes espessuras foram realizadas controlando-se o número de ciclos utilizados para a preparação do eletrodo modificado. Curvas cronoamperométricas foram registradas em solução contendo o eletrólito suporte + bromato $0,6 \mathrm{mM}$ para eletrodos com filmes de diferentes espessuras e observou-se que a corrente catalítica aumenta significativamente trabalhando-se com filmes cuja preparação envolveu de 5 a 20 ciclos (de $+0,20$ a $-0,90 \mathrm{~V}$ a $200 \mathrm{mV} / \mathrm{s}$ ). Para filmes mais espessos (de 20 a 100 ciclos) observou-se um ligeiro aumento na corrente catalítica, mas muito menos acentuado do que para filmes mais finos. Tal fato deve, provavelmente, ser devido à dificuldade de acesso do substrato aos sítios catalíticos do mediador imobilizado em filmes mais espessos como resultado de menor hidratação ou porosidade do depósito. Outra possibilidade referese à ocorrência de modificações estruturais ou de composição do filme durante o tempo necessário para gerar os filmes de diferentes espessuras.

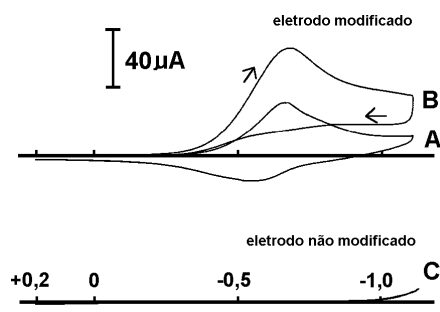

POTENCIAL / V

Figura 4. Voltamogramas de solução contendo $\mathrm{Na}_{2} \mathrm{SO}_{4} 50 \mathrm{mM}+\mathrm{H}_{2} \mathrm{SO}_{4}$ $(\mathrm{pH}=3,05)$ antes $(A)$ e após $(B, C)$ adição de bromato $2 \mathrm{mM}$ obtidos com eletrodo de carbono vítreo $(C)$ e eletrodo modificado por filme de molibdênio preparado pela ciclagem (10 ciclos) em solução contendo o eletrólito suporte $+\operatorname{Mo}(V I) 1 \mathrm{mM}(A, B)$. Velocidade de varredura $=100 \mathrm{mV} / \mathrm{s}$.

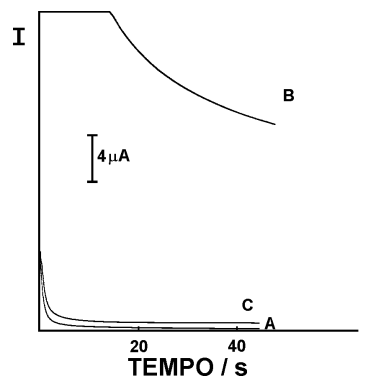

Figura 5. Cronoamperogramas de solução de $\mathrm{Na}_{2} \mathrm{SO}_{4} \mathrm{mM}+\mathrm{H}_{2} \mathrm{SO}_{4}$ $(\mathrm{pH}=3,05)$ antes $(A)$ e após $(B, C)$ adição de bromato $2 \mathrm{mM}$. Eletrodo de carbono vítreo $(C)$, eletrodo modificado por filme de molibdênio (10 ciclos de potencial em solução contendo eletrólito suporte + Mo(VI) $1 \mathrm{mM}(\mathrm{A}, \mathrm{B})$. Pulso de potencial: +0,20 a -0,60 V.
Estudos envolvendo a possibilidade do filme de molibdênio catalisar a redução de outros ânions oxigenados também foram executados. Empregou-se filme formado em eletrodo de carbono vítreo após 5 ciclos de potencial $(+0,20 \mathrm{a}-1,00 \mathrm{~V})$ em solução contendo $\mathrm{Mo}(\mathrm{VI}) 1 \mathrm{mM}+\mathrm{H}_{2} \mathrm{SO}_{4} 1 \mathrm{mM}+\mathrm{Na}_{2} \mathrm{SO}_{4} 50$ $\mathrm{mM}$. Cronoamperogramas do eletrodo modificado foram registrados em solução sulfúrica $(\mathrm{pH}=3)$ contendo $\mathrm{Na}_{2} \mathrm{SO}_{4} 50 \mathrm{mM}$ antes e apó a adição de soluções dos seguintes oxi-ânions, suficiente para gerar soluções $1 \mathrm{mM}$ : nitrito, nitrato, clorato, perclorato e iodato. Observou-se variação significativa do sinal analítico condizente com a existência de processo catalítico apenas após adição de iodato, ratificando dados da literatura os quais correlacionam o poder oxidante de ânions oxigenados em relação a compostos reduzidos de molibdênio com a polarizabilidade do átomo central na molécula do substrato ${ }^{23}$.

\section{Estudos couloméricos envolvendo redução do bromato}

Estudos coulométricos foram executados com solução de $\mathrm{Mo}(\mathrm{VI}) 1 \mathrm{mM}$ em $\mathrm{H}_{2} \mathrm{SO}_{4} 10 \mathrm{mM}$ com a intenção de verificar se a redução do substrato pelo filme de molibdênio conduzia à geração de brometo. Um experimento inicial consistiu no registro da corrente em função do tempo durante a aplicação de potencial constante $(-0,60 \mathrm{~V})$ trabalhando-se com a solução sem bromato, com o objetivo de se descontar a carga referente ao processo eletroquímico de redução do Mo(VI). Observou-se, após 10 minutos de eletrólise, a formação de um filme bastante escuro na superfície do disco de carbono vítreo, característico do depósito dos óxidos de molibdênio. Antes e após execução do experimento coulométrico, voltamogramas da solução de trabalho foram registrados utilizando-se um microeletrodo de mercúrio, não se observando qualquer processo eletroquímico antes da oxidação do mercúrio em $+0,4 \mathrm{~V}$. Com a adição posterior de brometo em quantidades adequadas para originar soluções 1 e 3 x $10^{-5} \mathrm{M}$ obtiveram-se os voltamogramas de estado estacionário referentes à antecipação da oxidação anódica do mercúrio na presença do haleto (Figura 6A, voltamogramas c e d).

$\mathrm{O}$ experimento coulométrico acima descrito foi repetido utilizando-se o mesmo eletrólito suporte contendo Mo(VI) + bromato $1 \mathrm{mM}$. Durante o processo de aplicação de potencial a corrente registrada foi significativamente maior devido ao processo catalítico e esta foi integrada graficamente após 10 minutos de eletrólise, obtendo-se desta forma a corrente referente à redução do substrato após desconto da carga relativa ao branco. O voltamograma da solução de trabalho foi registrado utilizando-se o microeletrodo de mercúrio, observando-se o aparecimento de onda anódica após o processo eletrolítico e confirmando a geração de brometo em solução (Figura 6B, voltamograma b). Todavia, a comparação da altura desta onda anódica com a altura das ondas obtidas adicionando-se quantidades conhecidas de brometo conduziu a uma concentração de brometo da ordem de $1 \times 10^{-5} \mathrm{M}$, ou $2 \times 10^{-7}$ mols considerando-se o volume da solução de trabalho $(20 \mathrm{ml})$. Este valor foi bastante inferior àquele esperado teoricamente levando-se em conta a carga envolvida no processo de redução do bromato $(3,6$ C) e a participação de 6 elétrons no processo redox de acordo com a seguinte equação:

$$
\mathrm{BrO}_{3}^{-}+6 \mathrm{H}^{+}+6 \mathrm{e}^{-} \rightleftharpoons \mathrm{Br}^{-}+3 \mathrm{H}_{2} \mathrm{O}
$$

Explicações para tal discrepância envolvem a redução não quantitativa do substrato a brometo em meio de $\mathrm{H}_{2} \mathrm{SO}_{4} 10 \mathrm{mM}$, com conseqüente formação de intermediários oxigenados de bromo alguns dos quais têm sido relatados na literatura ${ }^{25}$. Proposta semelhante foi discutida em estudo cinético relacionado à redução de bromato por ions de vanádio (IV), no qual os autores sugerem que a etapa lenta do processo global de redução envolva a abstração de um átomo de oxigênio, formandose o radical $\mathrm{BrO}_{2}{ }^{26}$. 


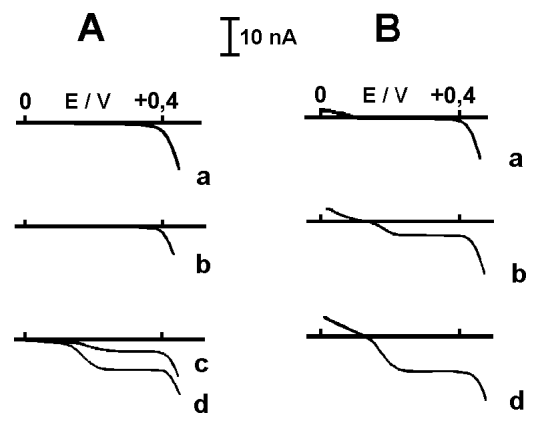

Figura 6. Voltamogramas obtidos em solução de $\mathrm{H}_{2} \mathrm{SO}_{4} 10 \mathrm{mM}+$ $M o(V I) 1 \mathrm{mM}$ antes $(A)$ e após $(B)$ adição de bromato $1 \mathrm{mM}$ registrados com microeletrodo de mercúrio. Os voltamogramas foram registrados antes $(a)$ e após $(b)$ experimento coulométrico $(E=-0,60 \mathrm{~V})$. Voltamogramas $(c)$ e $(d)$ foram registrados com a solução resultante do experimento coulométrico após adição de $1 \times 10^{-5} \mathrm{M}(\mathrm{c})$ e $3 \times 10^{-5} \mathrm{M}(\mathrm{d})$ de bromato (concentração final em solução).

\section{CONCLUSÕES}

Os experimentos apresentados neste trabalho mostraram que a deposição eletroquímica de óxidos mistos de molibdênio em meio sulfúrico constitui-se num método bastante favorável para modificação de superfícies de carbono vítreo. A estabilidade química e mecânica destes filmes em determinadas condições experimentais, aliada à relativa porosidade e atividade catalítica diante de ânions como bromato, permitiram o desenvolvimento de método analítico bastante reprodutivo e relativamente sensível para a determinação deste substrato. Metodologias mais sensíveis para a quantificação deste analito em amostras sintéticas e naturais estão sendo desenvolvidas empregando-se procedimento em fluxo, no qual a detecção amperométrica será efetuada com base em eletrodo modificado pelo filme de molibdênio.

Em meio não muito ácido $\left(10 \mathrm{mM}\right.$ em $\left.\mathrm{H}_{2} \mathrm{SO}_{4}\right)$ observou-se que brometo não é o único produto formado via redução do bromato, o que leva à suspeita sobre a existência de outros intermediários bromados gerados na etapa de redução do substrato pelos óxidos reduzidos de molibdênio. Neste processo, a interação química do mediador com o substrato deve basear-se em etapas de hidrogenação ou abstração de átomos de oxigênio e embora a composição exata do depósito não tenha sido investigada com mais detalhes os candidatos mais prováveis incluem compostos do tipo $\mathrm{MoO}_{3-\mathrm{x}}$ ou $\mathrm{H}_{\mathrm{x}} \mathrm{MoO}_{3}$. Em ambos os casos, é provável que a transferência de elétrons envolva a ligação entre orbital $\mathrm{p}$ do oxigênio do substrato e orbital d do molibdênio com formação de intermediário cuja cinética de formação pode constituir-se na etapa lenta do processo catalítico.

\section{AGRADECIMENTOS}

Os autores agradecem à FAPESP o apoio financeiro concedido a MB durante estada em Southampton.

\section{REFERÊNCIAS}

1. Zak, J.; Kuwana, T.; J. Electroanal. Chem. 1983, 150, 645.

2. Murray, R. C.; Electroanal. Chem. 1984, 13, 191.

3. Murray, R. C.; Ewing, A. G.; Durst, R. A.; Anal. Chem. 1987, 59, 379A.

4. Faulkner, L. R.; Electrochim. Acta 1989, 34, 1699.

5. Cox, J. A.; Jaworski, R. K.; Kulesza, P. J.; Electroanalysis 1991, 3, 869.

6. Kulesza, P. J.; Faulkner, R.; J. Am. Chem. Soc. 1988, $110,4905$.

7. Dong, S. J.; Wang, B. X.; J. Electroanal. Chem. 1994, $370,141$.

8. Wang, B. X.; Dong, S. J.; J. Electroanal. Chem. 1994, 379, 207.

9. Kulesza, P. J.; Faulkner, R.; Colloids and Surfaces 1989, $41,123$.

10. Bertotti, M.; Pletcher, D.; Electroanalysis 1996, 8, 1105.

11. Furman, N. H.; Murray, W. M.; J. Am. Chem. Soc. 1936, $58,1689$.

12. Wehmeyer, K. R.; Wightman, R. M.; Anal. Chem. 1985, 57, 1989.

13. Wightman, R. M.; Wipf, D. O.; Electroanal. Chem. 1989, $15,267$.

14. Stiefel, E. I.; Prog. Inorg. Chem. 1977, 22, 1.

15. Brown, P. L.; Shying, M. E.; Sylva, R. N.; J. Chem. Soc. Dalton Trans. 1987, 2149.

16. Bertotti, M.; Tokoro, R.; J. Electroanal. Chem. 1993, 360, 39.

17. Bertotti, M.; Pletcher, D; submetido para publicação nos Anais da $A B Q$.

18. Himeno, S.; Saito, A.; J. Electroanal. Chem. 1983, 152, 163.

19. Ogura, K.; Enaka, Y.; Morimoto, K.; Electrochim. Acta 1978, 23, 289.

20. Barbara, T. M.; Gammie, G.; Lyding, J. W.; Jonas, J.; J. Solid State Chem. 1988, 75, 183.

21. Machida, K.; Enyo, M.; J. Electrochem. Soc. 1990, 137, 1169.

22. Eda, K.; J. Solid State Chem. 1992, 98, 350.

23. Lahr, S. K.; Finklea, H. O.; Schultz, F. A.; J. Electroanal. Chem. 1984, 163, 237.

24. Toropova, V. F.; Vekslina, V. A. J.; J. Anal. Chem. USSR 1975, 30, 271.

25. Cotton, F. A.; Wilkinson, G.; Advanced Inorganic Chemistry; 5th edition; John Wiley \& Sons, New York, 1988.

26. Fuller, C. W.; Ottaway, J. M.; Analyst 1969, 94, 32. 